\title{
Iron-containing Adsorbents in Great Nile Sediments
}

\author{
T. M. Meaz, M. A. Amer ${ }^{1}$, and C. Bender Koch ${ }^{2}$ \\ ${ }^{1}$ Physics Department, Faculty of Science, Tanta University, Tanta, Egypt \\ ${ }^{2}$ Chemistry Department, The Royal Veterinary and Agricultural \\ University, Frederiksberg, Denmark
}

A sample from the Great Nile (near Khartoum) has been investigated by Mössbauer spectroscopy, infrared spectroscopy, analytical electron transmission microscopy and X-ray diffraction aiming to evaluate potential iron-containing sinks for heavy metal adsorption. The phyllosilicate fraction is dominated by highly-oxidized illite/smectite and the oxide fraction is dominated by defective goethite and hematite (as evidenced from low ordering temperatures and line broadening effects).

\section{Introduction:}

The Great Nile River has two major water and sediment sources: The Blue Nile and the White Nile. Water and sediment transport is mainly facilitated though the Blue Nile originating in Ethiopia. Broadly speaking the Blue Nile transported sediment reflects the weatherings of the basalt dominated bedrocks and are thus expected to contain secondary iron-containing minerals. Among these, particular interest is devoted to the ultra fine iron oxides known to function as adsorbents in various geochemical settings.

The Great Nile is essentially the only waterway though the intensely populated Nile Valley and functions as source of water and recipient of pollutants. Thus the adsorption properties and the dynamics of the adsorbents becomes a crucial point in understanding and evaluating the Great Nile geochemical system. Mössbauer spectroscopy has previously been applied to biogeochemical problems involving $\mathrm{Fe}$ and clay [1-11].

We here report a study of the sediments entering the Great Nile River system by investigating a sample from the River bed sampled at Khartoum, Sudan i.e. after the confluence of the Blue and White Rivers. 


\section{Material and Experimental:}

A sediment sample was obtained from the Great Nile River bed downstream of Khartoum after the confluence of the Blue and White Nile in Sudan. The sample was dried at room temperature prior to analysis by $\mathrm{x}$-ray powder diffraction, analytical transmission electron microscopy, infrared spectroscopy and Mössbauer spectroscopy. The sampling location is shown in Fig. (1). Mössbauer spectra were obtained using a constant acceleration spectrometer with $50 \mathrm{mCi}{ }^{57} \mathrm{Co}$ in $\mathrm{Rh}$. The spectrometer was calibrated using a thin foil of natural Fe at room temperature. Spectra were measured between RT and $5 \mathrm{~K}$.

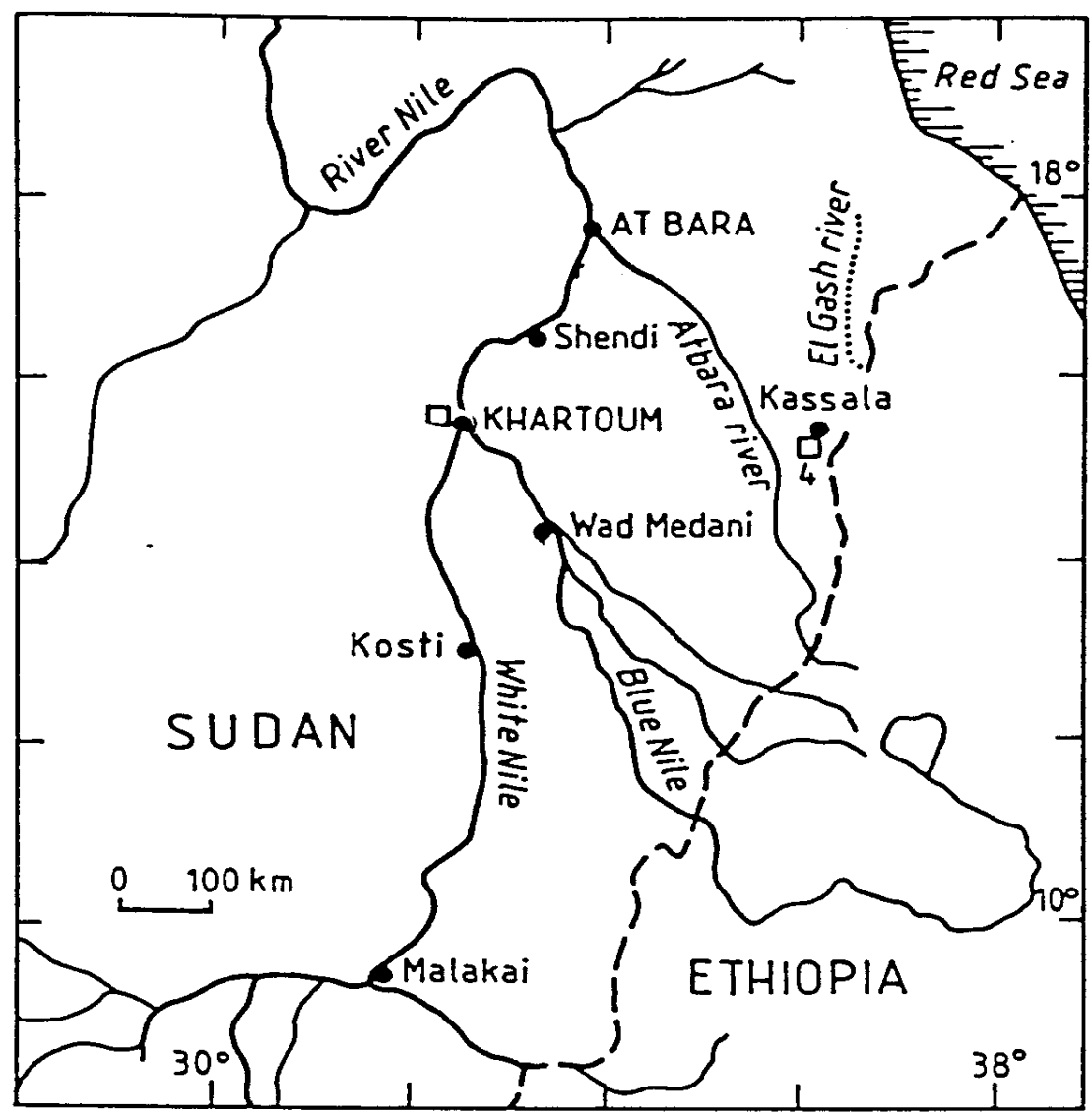

Fig. (1): Sampling site from the Great Nile River near Khartoum, Sudan.

The transmission electron microscope was equipped with an $\mathrm{x}$-ray energy dispersive detector allowing quantifying elements with $\mathrm{Z}$ larger than or equaling to $\mathrm{Na}$. 


\section{Results and discussion.}

The X-ray diffraction pattern of the random powder sample is shown in Fig. (2). It shows a number of sharp and broad diffraction lines caused by differences in crystal size and perfection. Among the sharp lines peaks due to the primary minerals quartz $(\mathrm{Q})$ and feldspars $(\mathrm{F})$ are detected, and among the broad lines the secondary minerals smectite $(\mathrm{Sm})$, kaolinite $(\mathrm{K})$ and illite (I) can be identified (common lines designated to phyllosilicates $(\mathrm{P})$. Infrared spectroscopy (not shown) verified kaolinite, illite, and smectite as the dominant phyllosilicates. The iron oxides are present only below the detection limits of the methods.

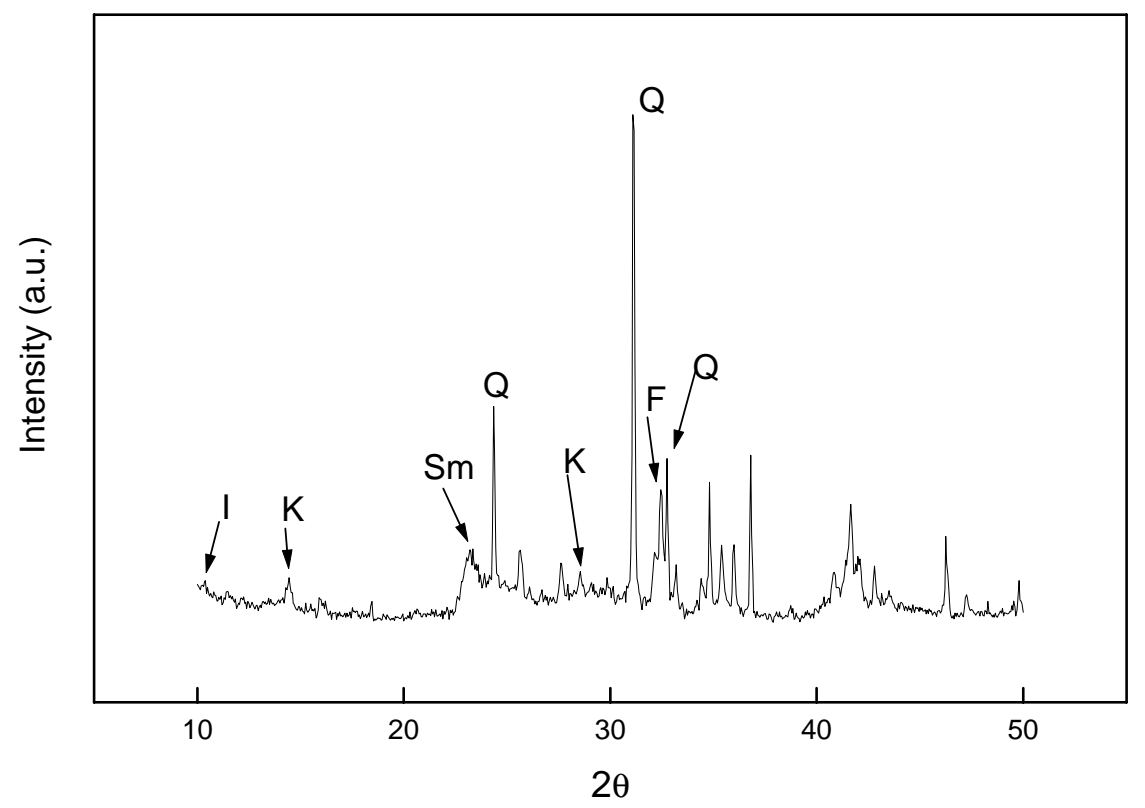

Fig. (2): X-ray powder diffraction pattern of the Great Nile River sample.

Analytical transmission electron microscopy revealed highly fluctuating analysis as expect from such a multi component system. The element analysis by EDX revalued the presence of $\mathrm{Na}, \mathrm{Mg}, \mathrm{Al}, \mathrm{Si}, \mathrm{K}, \mathrm{Ca}$, Ti and $\mathrm{Fe}$ and the results from different particles are given in Table (1). It is interesting to note the ubiquitous presence of $\mathrm{Fe}$ in point analysis of quartz (approx. $3 \mathrm{wt} \%$ ) and fairly high contents of Fe in the phyllosilicates (15 wt\%). No iron oxides were detected as separate particles. These observations indicate an intimate 
association of the iron oxides with both the primary and secondary silicates, probably dominantly via surface associations.

Table (1): Major elements from analysis of four composite.

\begin{tabular}{|c|r|r|r|r|r|r|}
\hline Element & L1 (wt\%) & L2 (wt\%) & L3 (wt\%) & L4 (wt\%) & Av. (wt\%) & St.Dev. \\
\hline $\mathrm{Na}$ & 3.11 & 4.69 & 4.58 & -- & 4.13 & 0.72 \\
\hline $\mathrm{Mg}$ & 1.85 & 3.68 & 1.06 & 5.11 & 2.92 & 1.57 \\
\hline $\mathrm{Al}$ & 7.69 & 14.74 & 25.55 & 20.33 & 17.0 & 6.63 \\
\hline $\mathrm{Si}$ & 80.06 & 45.43 & 48.47 & 48.31 & 55.57 & 14.19 \\
\hline $\mathrm{K}$ & 0.26 & 0.88 & 1.08 & 2.02 & 1.06 & 0.63 \\
\hline $\mathrm{Ca}$ & 3.82 & 17.74 & 15.69 & 8.68 & 11.48 & 5.55 \\
\hline $\mathrm{Ti}$ & -- & 3.19 & 0.31 & 0.94 & 1.48 & 1.23 \\
\hline $\mathrm{Fe}$ & 3.18 & 9.60 & 3.21 & 14.58 & 7.64 & 4.78 \\
\hline
\end{tabular}

The Mössbauer spectra of the sample are shown in Fig. (3). At all temperatures magnetically ordered sextets, ferric and ferrous doublets coexists. The very small amount of ferrous components detected points to weathering in a highly oxidized environment in the basalt. The relative intensity of the magnetically ordered components increases with lowering the temperature, indicating influence by substitution and size effects on the spectra. The parameters of the ferric and ferrous doublet at $5 \mathrm{~K}$ (isomer shifts of $0.47 \mathrm{mms}^{-1}$ and quadrupole splitting of $0.57 \mathrm{mms}^{-1}$ for the ferric component and isomer shifts of $1.32 \mathrm{mms}^{-1}$ and quadrupole splitting of $2.57 \mathrm{mms}^{-1}$ for the ferrous component) are within the parameters previously reported for phyllosilicates [9]. At 5 and $22 \mathrm{~K}$ the magnetically ordered part seems to consist of two overlapping sextets with fairly sharp lines. Magnetic hyperfine fields of 48.8 and 51.7 T, respectively, indicate the presence of substituted hematite $\left(\alpha-\mathrm{Fe}_{2} \mathrm{O}_{3}\right)$ and goethite $(\alpha-\mathrm{FeOOH})$ in almost equal amounts as indicated from the intensities. The total amount of $\mathrm{Fe}$ approx. $50 \%$ is in the oxide fraction. At higher temperatures strong asymmetries develop in the lines of both components. At $80 \mathrm{~K}$ in particular the low-field component (goethite) shows extensive line broadening. The finding of magnetic hyperfine field reduction together with lowering of ordering temperature and absence of a Morin transition indicates that the broadening is related to the substitution in the lattice. Moreover, it is known that $\mathrm{Al}$ substituted iron affect the Morin transition. At room temperature the hematite component consists of two components: a rather sharp lined one causing the appearance of a marked maximum and another one causing asymmetric lines. This suggests the possible presence of hematite with two different levels of substitution or crystal sizes. We suggest tentatively that the well crystalline hematite is inherited directly from the basaltic rock, whereas the poorly crystalline hematite formed during weathering. 


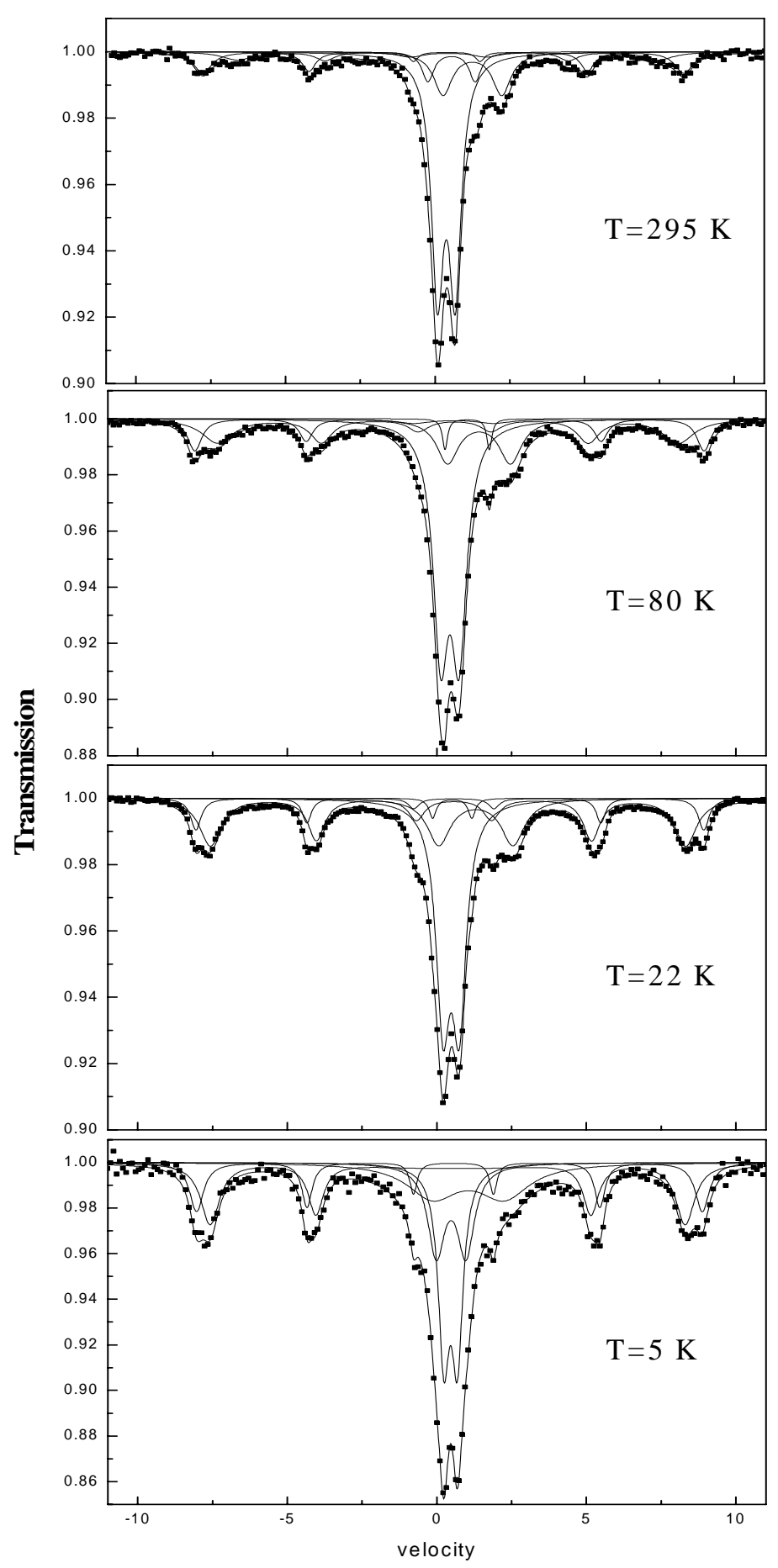

Fig. (3): Mössbauer spectra of the Great Nile River sample obtained at the indicated temperatures. 


\section{Conclusion:}

The fine-grained iron oxide in the sediments from the Great Nile has been identified in this pilot study by Mössbauer spectroscopy. We find that goethite and hematite are present in almost equal amounts. Both minerals are expected to be highly surface reactive due to their dominantly small crystal size.

\section{References:}

1. Mijovilovich, H. Morras, H. Causevic and C. Saragovi, Hyp. Int., 122, 83 (1999).

2. C.C. Muggler, J.J. Van Loef, P. Buurman, J.D.J. Van Doesburg, Geoderma, 100, 147 (2001).

3. D. G.. Rancourt, Hyp. Int., 117, 3 (1998).

4. E. Murad, Hyp. Int., 117, 39 (1998).

5. Bender Koch, Hyp. Int., 117, 131 (1998).

6. Sahi Ram, K.R. Patel, S.K. Sharma and R.P. Tripathi, Fuel, 76 (14/15), 1369 (1997).

7. E. Murad, Hyp. Int., 111, 251 (1998).

8. Bancroft, G. M. "Mössbauer Spectroscopy- an introduction for inorganic chemists and Geochemists", McGraw-Hill, London, 232 (1973).

9. Coey, J.M.D. in Mössbauer Spectroscopy Applied to Inorganic Chemistry (Ed. by G. J. Long) Vol. 1, Plenum Press, New York, 443 (1984).

10. Russo, U., Carbonin, S., and Della Giusta, A., "Mössbauer Spectroscopy Applied to Magnetism and Material Science" (Ed. by G.J. Long and F. Grandjean), vol. 2, Plenum Press, New York, 207 (1996).

11. N. A. Eissa, S. Sh. Gomaa, M.Y. Hassan and H. A. Sallam, Hyp. Int., 41, 775 (1988). 